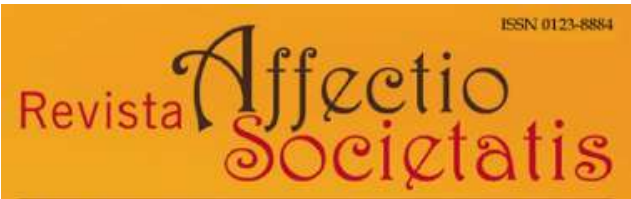

Departamento de Psicoanálisis | Universidad de Antioquia

Revista Affectio Societatis

Departamento de Psicoanálisis

Universidad de Antioquia

revistaaffectiosocietatis@udea.edu.co

ISSN (versión electrónica): 0123-8884

Colombia

2021

Raúl Jiménez-Betancourt, Ricardo García Valdez

Acting out y pasaje al acto. Hacia una ética del acto suicida Revista Affectio Societatis, Vol. 18, N. ${ }^{0} 34$, enero-junio de 2021

Art. \# 1 (pp. 1-25)

Departamento de Psicoanálisis, Universidad de Antioquia Medellín, Colombia 
ARTÍCULO DE INVESTIGACIÓN

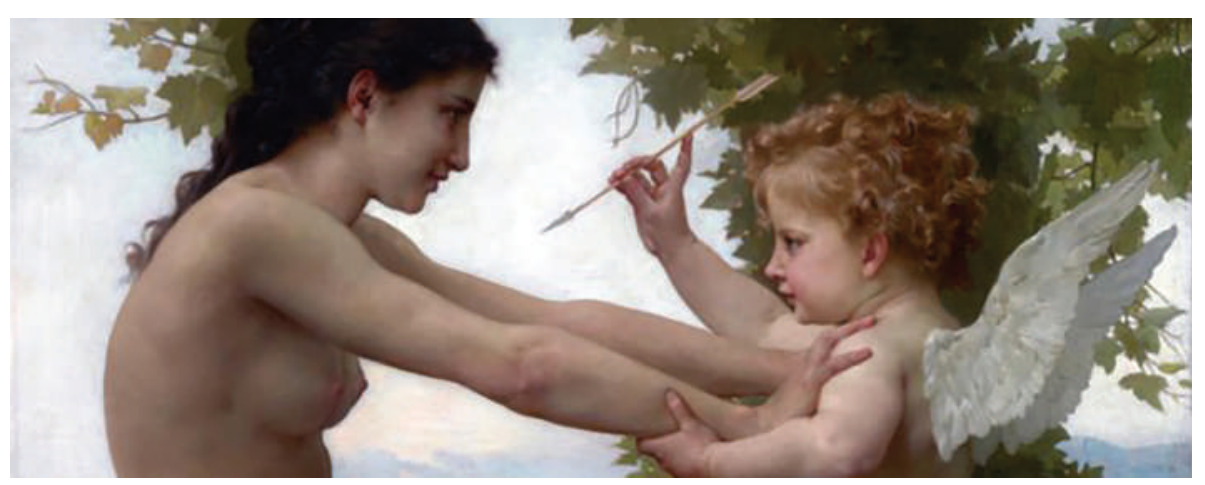




\title{
ACTING OUTY PASAJE AL ACTO. HACIA UNA ÉTICA DEL ACTO SUICIDA ${ }^{1}$
}

\author{
Raúl Jiménez-Betancourt ${ }^{2}$ \\ Universidad Veracruzana, México \\ ra.jbv333@gmail.com \\ https://orcid.org/0000-0002-8177-7406
}

Ricardo García Valdez ${ }^{3}$

Universidad Veracruzana, México

rigarcia@uv.mx

https://orcid.org/0000-0001-8955-4453

DOI: 10.17533/udea.affs.v118n34a01

\section{Resumen}

El presente artículo es resultado de una investigación doctoral sobre el suicidio en un recorrido que va de Freud a Lacan, siguiendo el hilo conductor de una pregunta que no presupone el deseo de vivir como natural. A partir de la revisión y articulación de tres conceptos (acting out, pasaje al acto y acto) en la enseñanza de Lacan se realiza una propuesta di- vergente al manto de moral y psicopatologización que se extiende -aun en ocasiones dentro del mismo psicoanálisis- sobre el suicidio. Se franquean los límites de la clasificación para desplegar la superficie hacia una ética del acto suicida.

Palabras clave: acting out, pasaje al acto, acto, suicidio, ética.

1 Este artículo es resultado parcial de la tesis doctoral "Hacia una ética del acto suicida. De la pulsión de muerte en Freud al suicidio en la enseñanza de Lacan" adelantada en la Universidad Veracruzana, México, desde 2017 hasta la actualidad.

2 Psicoanalista. Mtro. en Psicoanálisis y cultura por la Escuela Libre de Psicología. Egresado del doctorado en Psicología por la Universidad Veracruzana. Miembro fundador del colectivo Acto Analítico. Estancia doctoral en la facultad de filosofía de la Universidad Complutense de Madrid.

3 Psicoanalista. Doctor en Ciencias Sociales. Investigador de Instituto de Investigaciones Psicológicas de la Universidad Veracruzana. Director de la Revista Electrónica Psicoanalítica de la Universidad Veracruzana. Director del Instituto de Investigaciones Psicológicas de la Universidad Veracruzana. 


\section{ACTING OUT AND PASSAGE TO THE ACT. TOWARDS AN ETHICS OF THE SUICIDAL ACT}

\section{Abstract}

This paper is the result of a doctoral research on suicide in a journey that goes from Freud to Lacan, following the common thread of a question that does not presuppose the desire to live as natural. From the review and articulation of three concepts (acting out, passage to the act, and act) in Lacan's teaching, it makes a proposal divergent from the moral and psychopathologizing mantle that extends -even sometimes within psychoanalysis itself- over suicide. The limits of classification are crossed in order to unfold the surface towards and ethics of the suicidal act.

Keywords: acting out, passage to the act, act suicide, ethics

\section{ACTING OUTET PASSAGE À L'ACTE. VERS UNE ÉTHIQUE DE L'ACTE SUICIDAIRE}

\section{Résumé}

Cet article est le résultat d'une recherche doctorale sur le suicide qui parcourt les approches de Freud à Lacan, en suivant comme fil conducteur une question qui ne présuppose pas le désir de vivre comme étant naturel. À partir de la révision et de l'articulation de trois concepts (acting out, passage à l'acte et acte) dans l'enseignement de Lacan, l'on propose une approche qui s'éloigne d'un regard moral et psychopathologique présent - parfois dans la psychanalyse elle-même- sur le suicide. Les limites de la classification sont franchies afin d'étendre le champ d'analyse vers une éthique de l'acte suicidaire.

Mots-clés : acting out, passage à l'acte, acte, suicide, éthique. 


\section{ACTING OUTE PASSAGEM AO ATO. EM PROCURA DE UMA ÉTICA DO ATO SUICIDA}

\section{Resumo}

O presente artigo é o resultado de da moral e da psicopatologização que uma pesquisa de doutorado sobre o se estende - mesmo às vezes dentro suicídio numa trajetória que vai de da psicanálise por si próprio - sobre Freud a Lacan, seguindo o fio de uma o suicídio. Os limites de classificação pergunta que não pressupõe o dese- são cruzados a fim de desdobrar a sujo de viver como uma coisa natural. perfície em direção a uma ética do ato Partindo da revisão e articulação de suicida.

três conceitos (acting out, passagem ao ato e ato) no ensino de Lacan, uma proposta divergente é feita ao manto

Palavras-chave: acting out, passagem ao ato, ato, suicídio, ética.

Recibido: 11/25/2019 • Aprobado: 9/7/2020 
Me extraña que se busque una jerarquía de suicidios: nada es más estúpido que desear clasificarlos según la nobleza o la vulgaridad de sus causas. ¿No es lo suficientemente impresionante en sí el hecho de quitarse la vida para que se anden buscando motivos?

Emil Cioran, En las cimas de la desesperación.

Lo más importante de seguir el hilo conductor de una pregunta es que lleve a interrogar el lugar mismo desde donde esta se realiza. Nuestra investigación ha planteado la posibilidad de hallar puntos permeables a la moral dominante y a la psicopatologización del suicidio dentro del psicoanálisis. Aquí, por motivos de extensión, nos enfocaremos en uno: la clasificación a partir de los conceptos acting out, pasaje al acto y acto. Por otra parte, no se trata de una acusación de que tal distinción conceptual para pensar el suicidio sea en sí misma moral ni psicopatológica, sino de una advertencia del viraje del que puede ser objeto si no se precisa lo suficiente. Se trata, pues, de insistir en una consecuencia posible del pensamiento de Lacan, que a menudo es soslayada: la apertura a las multiplicidades.

\section{Acting out}

El término acting out es un anglicismo dentro del vocabulario psicoanalítico que proviene de la expresión freudiana Agieren. Esta última aparece por primera vez en el texto "Fragmento de análisis de un caso de histeria" (el caso Dora), para referirse a la interrupción del tratamiento por parte de la paciente. Freud (1992/1905) interpretó la acción como una venganza hacia el señor K., llevada a cabo, vía transferencial, a través de la figura del analista.

Así fui sorprendido por la trasferencia $\mathrm{y}$, a causa de esa $\mathrm{x}$ por la cual yo le recordaba al señor K., ella se vengó de mí como se vengara de él, y me abandonó, tal como se había creído engañada y abandonada por él. De tal modo, actuó \{agieren\} un fragmento 
esencial de sus recuerdos y fantasías, en lugar de reproducirlo en la cura. (pág. 104).

En sentido estricto, Freud no habló de acting out. Agieren se traduce literalmente al español como el verbo transitivo actuar. Acting out es la forma sustantivada del verbo en inglés to act out. El acting out involucraría una actuación que adviene en el lugar de la asociación de ideas; es decir, del campo de la palabra que el dispositivo analítico posibilita. Además, es una actuación que irrumpe en el patrón de conducta del individuo, pero que tiende a ser repetitiva. A diferencia del síntoma, el sujeto del acting out no se pregunta por su sentido.

En el Diccionario de psicoanálisis, de Laplanche y Pontalis (2004/1967), aparecen algunas precisiones semánticas importantes en torno al acting out: la primera, to act refiere principalmente a significaciones del ámbito teatral (ej., to act a play es representar una obra, to act a part es representar un papel); la segunda, el vocablo out, cuando es utilizado después de un verbo, tiene dos matices: exteriorizar y realizar rápidamente hasta la terminación una acción (ej., spit out es escupir, clean out es dejar limpio). El primer matiz de out ha llevado al equívoco de pensar que el acting out sería lo que sucede por fuera del consultorio. De otro lado, no hay vocablo en español ni en francés que posea estos matices.

El acting out tiene la característica de ser una acción mostrativa. Dice Lacan (2007/1962-1963) durante su Seminario 10, La angustia (clase del 23 de enero del 63), que: "El acting out es esencialmente algo, en la conducta del sujeto, que se muestra. El acento demostrativo de todo acting out, su orientación hacia el Otro, debe ser destacado" (pág. 136). El acting out es un llamado al Otro en un contexto transferencial, y es bien sabido que se requiere transferencia para que haya análisis, mas no se requiere análisis para que haya transferencia. “El acting out llama a la interpretación, pero la cuestión es, ciertamente, saber si ésta es posible. Les mostraré que sí, pero plantea dudas, tanto en la práctica como en la teoría analíticas" (pág. 139).

La amenaza de suicidio de un paciente durante una sesión podría ejemplificar un acting out: instar a que recapacite sería lo esperable 
de alguien que opera desde lo que Foucault (2007/1973-1974) llamó la función psi (psiquiatras, psicólogos y también psicoanalistas), o lo que ahora son los modelos de salud mental, pero esa no sería una intervención analítica per se (aunque en el análisis la regla sea la excepción y aunque una condición necesaria para que haya análisis es que el analizante esté, por lo menos, vivo). El análisis tendría que ir más allá de la función psi. Es claramente complicado, pues un evento tal puede dislocar al analista de su lugar de objeto $a$ y hacerlo aparecer como sujeto barrado: p. ej., preguntarse por su prestigio y/o por su calidad de ser humano si permite que un paciente o analizante se suicide. Por ello es importante que un analista tenga en cuenta los límites de un dispositivo que es por sí mismo apertura a otras vías. El acto analítico es un comienzo de otra relación del sujeto con su deseo. Es una invitación a tomar la palabra un día más y la posibilidad de que el objeto de las más sofisticadas fantasías suicidas caiga de otra manera que lanzándose de un puente: “-Hoy me dispararé con la pistola de mi padre -¿Por qué con la de su padre precisamente?"

Lacan precisa que en el acting out "no es el sentido, sea cual sea, de lo que interpretan ustedes lo que cuenta, sino el resto" (pág. 140). ¿Cuál es ese resto? ¿Qué es lo que el acting out muestra al Otro? Aquello ignorado, el objeto petit a, causa del deseo. A propósito, Lacan (2007/1962-1963) señala ciertas coordenadas:

Adviertan ustedes en sus observaciones clínicas hasta qué punto sostener con la mano para no dejar caer es del todo esencial en cierto tipo de relaciones del sujeto. Cuando den con algo así, pueden estar absolutamente seguros de que es un $a$ para el sujeto. Esto produce uniones de un tipo muy extendido, que no por ello son más cómodas de manejar, ya que por otra parte el $a$ en cuestión puede ser para el sujeto el superyó más incómodo. (pág. 136).

Ciertamente, el superyó en tanto voz puede estar funcionando para el sujeto como objeto $a$ : la melancolía es un claro ejemplo. Al suicidio melancólico lo hemos propuesto como una forma de insurrección: el suicida asesina al tirano superyó vía la identificación suicida, le niega perpetuar su imperativo de goce en un acto culminante para emerger, a posteriori, como sujeto. Lo trágico es que para ello debe 
atravesar su propia imagen, su amor propio: $i(a)$, por lo que al final "es el objeto el que triunfa" (pág. 363). Pero pensarlo como sedición contra un tirano se distingue del paradigma freudiano del suicidio como crimen contra uno mismo (pulsiones agresivas destinadas a otros se vuelcan sobre sí). Podría decirse que retomamos a Freud contra Freud; y así, el suicidio melancólico se aleja de la patología y nos aparece en su dimensión ética y política.

Hay otro elemento a resaltar en el acting out y es su carácter correctivo. Lacan (2007/1962-1963) propone dos fórmulas convergentes: "La transferencia sin análisis es el acting out. El acting out sin análisis es la transferencia" (pág. 139). El elemento en común a las dos es la ausencia de análisis, lo que puede entenderse como su ausencia material -consultorio, analizante, analista y cuota (que suele ser dinero, aunque no necesariamente)-, pero también como la presencia de sesión sin que haya propiamente una escucha analítica, p. ej., cuando la interpretación es inoportuna. De este modo, el acting out suicida se puede articular con una demanda de análisis cuyo correlato sería la función ética de una escucha muy singular que es la del analista. Pero una ética del acto suicida no podría ser reductible a la experiencia analítica en los consultorios privados, que no es osado afirmar que es limitada y las más de las veces elitista.

Concédasenos ahora el abordaje de cómo cierta comprensión del pasaje al acto sigue involucrando una patologización del suicidio.

\section{Del acting out al pasaje al acto}

Hemos señalado el origen del acting out en el Agieren freudiano; no obstante, este no se agota en aquel. Fenómenos comúnmente asociados al pasaje al acto también pueden caer bajo el conjunto Agieren. Esto tiene una razón histórica:

A medida que las ideas psicoanalíticas se difundían en Francia en la primera mitad del siglo $\mathrm{xx}$, se volvió común que los analistas franceses emplearan la expresión "pasaje al acto" para traducir el 
término Agieren utilizado por Freud: es decir, como sinónimo de ACTING OUT. (Evans, 2007, pág. 148).

Pero retomando el diccionario de Laplanche y Pontalis (2004/1967), la equivalencia entre acting out y pasaje al acto no se sostiene desde que este último es ocupado por la psiquiatría para referir al pasaje del pensamiento a la acción, generalmente en accesos de violencia y criminalidad:

El término «paso al acto», que es el equivalente más a menudo conservado, tiene, entre otros, el inconveniente de haber entrado ya en la clínica psiquiátrica, donde se tiende a reservarlo en forma exclusiva para designar actos impulsivos violentos, agresivos, delictivos (crimen, suicidio, atentado sexual, etc.); el sujeto pasa de una representación, de una tendencia, al acto propiamente dicho. Por otra parte, en su utilización clínica, este término no hace referencia a una situación transferencial. (pág. 6).

Estrictamente hablando, el pasaje al acto no es freudiano, es un vocablo de la psiquiatría francesa y es Lacan (2007/1962-1963) quien, en su Seminario 10, La angustia, lo convertirá en concepto psicoanalítico, diferenciándolo del acting out: "Todo lo que es acting out debe distinguirse del pasaje al acto" (pág. 135). Lo cual no significa que estos no puedan aparecer en contigüidad espacio-temporal, o incluso que aquel no sea la condición de posibilidad de este. A pesar de su precisa distinción teórica, el acting out está en posibilidad de desembocar en un pasaje al acto. Esto aparece en el abordaje realizado por Lacan (2007/19621963) del caso de la joven homosexual: piensa que el intento de suicidio (arrojarse del puente) es un pasaje al acto, mientras que sus paseos con la cocotte cerca del negocio de su padre eran acting out. ¿Cómo se da el movimiento del acting out al pasaje al acto? Se cumplen las dos condiciones del pasaje al acto: una identificación absoluta del sujeto con el objeto a y la confrontación del deseo con la ley. En este caso:

La confrontación del deseo del padre, en base al cual se construye toda su conducta, con la ley que se presentifica en la mirada del padre. Esto es lo que la hace sentirse definitivamente identificada con $a \mathrm{y}$, al mismo tiempo, rechazada, expulsada, fuera de la escena. Y esto, sólo puede realizarlo el dejar caer, el dejarse caer. (pág. 125). 
Lo importante de la lectura que hace Lacan del caso es que descentra el papel del Edipo. Ya no se trata tanto de parir el hijo deseado del padre, sino del embarazo como barra del sujeto. La identificación de la joven en el pasaje al acto es con la mirada del padre en tanto objeto $a$. Es una lectura estructural que rápidamente se articula con la melancolía (sin decir que la joven fuese melancólica):

El niederkommen es esencial en toda súbita puesta en relación del sujeto con lo que él es como $a$. No sin razón el sujeto melancólico tiene tal propensión, siempre llevada a cabo con una rapidez fulgurante, desconcertante, a arrojarse por la ventana. En efecto, la ventana, en tanto que nos recuerda el límite entre la escena y el mundo, nos indica lo que significa tal acto -de algún modo, el sujeto retorna a aquella exclusión fundamental en la que se siente. El salto se produce en el momento mismo en que se cumple, en lo absoluto de un sujeto que sólo nosotros, analistas, podemos concebir, la conjunción del deseo y la ley. (pág. 123).

Lacan eleva el intento de suicidio de esta joven al paradigma del pasaje al acto, lo cual significa que no todo pasaje al acto suicida lleva necesariamente a la muerte biológica. Por otro lado, a partir de la cita se entiende que el pasaje al acto es un intento radical de producir diferencia (en este caso, entre deseo y ley). No obstante, se sigue sosteniendo "el automatismo, el mecanismo, el carácter necesario y profundamente alienado con el que, como ustedes saben, se llevan a cabo los suicidios de melancólicos" (pág. 363).

Es que el uso del concepto pasaje al acto es inseparable de la formación de Lacan como médico psiquiatra. En su tesis doctoral, De la psicosis paranoica en sus relaciones con la personalidad, aborda el caso de Aimée y propone que el intento de asesinato a la actriz Huguette exDuflos fue un pasaje al acto. Según este Lacan (2005/1932), el pasaje al acto tuvo la función de curar el delirio a través de la autopunición:

Aimée ha realizado su castigo: ha experimentado lo que es esa compañía de delincuentes diversas a que se ha visto reducida; ha entrado en contacto brutal con sus hazañas, sus costumbres, sus opiniones y sus exhibiciones cínicas para con ella; ha podido palpar la reprobación y el abandono de todos los suyos; y de todos, con 
excepción de esas mujeres cuya vecindad le inspira una viva repulsión. Lo que Aimée comprende, entonces, es que se ha agredido a sí misma, y paradójicamente sólo entonces experimenta el alivio afectivo (llanto) y la caída brusca del delirio, que caracterizan la satisfacción de la obsesión pasional. (pág. 227).

Sin embargo, el 24 de noviembre de 1975 en la Universidad de Yale, Lacan (1975-1976) volverá al caso y se desdirá de puntos esenciales del diagnóstico:

Ella había herido un poco a esta actriz y fue enviada a prisión. Yo me permití a mí mismo ser coherente, y pensé que una persona que sabía siempre tan bien lo que hacía, sabía también a qué la llevaría eso, y es un hecho que su estadía en prisión la calmó. De un día para otro desaparecieron sus hasta entonces rigurosas elucubraciones. Yo me permití -tan psicótico como mi paciente- tomar esto en serio y pensar que, si la prisión la había calmado, ahí estaba lo que ella había realmente buscado. (pág. 6).

La psicosis de Lacan consistió en confundir el deseo con la prisión, siendo acaso esta última, más bien, el deseo del psiquiatra. Vemos que las primeras elucidaciones lacanianas del pasaje al acto dejaban ver su relación con un aspecto paradójico del paradigma freudiano del suicidio: sólo se puede dar muerte a uno mismo en tanto otro. $\mathrm{Y}$ es que el pasaje al acto por excelencia es un suicidio.

En su libro La invención lacaniana del pasaje al acto. De la psiquiatría al psicoanálisis, Pablo Muñoz (2009) realiza un magnífico recorrido de la construcción conceptual en Lacan, por lo que la cita merece toda la extensión:

En la tesis de 1932 el pasaje al acto es el medio para realización del autocastigo, entendido como satisfacción de la pulsión autopunitiva. En 1938, al dilucidar su estructura imaginaria como identificación del yo con su semejante, deviene un modo de resolver la tensión imaginaria suscitada por los fenómenos de intrusión narcisística, vale decir el sentimiento de alienación de sí mismo del yo en el semejante. Por último, en 1946, con el concepto de conocimiento paranoico, corrige la proposición de 1932 y extiende la propuesta 
de 1938 al sustituir el mecanismo de la autopunición por el de la agresión suicida del narcisismo, a partir de lo cual el pasaje al acto resulta el medio que el yo encuentra para fugarse del objeto que le presentifica su constitución alienada en el otro semejante, con el fin de eliminarlo para borrar su propia división. (pág. 230).

Se agregarían entonces nuevos elementos a la fórmula freudiana: la estructura paranoica del yo, que se resume en esta formidable y audaz frase: "Si un hombre cualquiera que se cree rey está loco, no lo está menos un rey que se cree rey" (Lacan, 2007/1950, pág. 161).

La agresión suicida del narcisismo es una expresión que aparece en una conferencia en 1946 y que luego será publicada con el nombre de "Acerca de la causalidad psíquica" en los Escritos. Dicha agresión es biyectiva y dialéctica: golpear al otro es golpearse a uno mismo, asesinarse a uno mismo es asesinar al otro. Cabe recordar lo que Freud nos dice en textos como "Duelo y melancolía", "Tótem y tabú" o en su abordaje en el caso de la joven homosexual: uno sólo puede matarse en tanto objeto. ¿Cuál es el problema de esta concepción? Que todavía no corta suficiente el lazo con la psiquiatría. Thomas Szasz (2002) nos resulta muy acertado en su crítica: “La generalización excesiva de Freud es un crudo recuerdo de la poderosa influencia de la tradición psiquiátrica religiosa: Freud trata el suicidio como si fuera un fenómeno unitario" (pág. 48). Se dice religiosa porque "en la concepción cristiana del mundo, la vida humana es un regalo de Dios y es de su propiedad. De ello se deduce que el suicidio es un autoasesinato, felo de se (una felonía contra uno mismo)" (págs. 69-70). No se trata de interpelar el ateísmo de Freud, sino que su comprensión del suicidio conserva esa ligadura con cierta criminalidad inherente. Ahora bien, el suicidio como pasaje al acto continúa arrastrando esa influencia y las líneas divisoras con la psiquiatría pueden desdibujarse, al grado de que hay analistas que llegan a hablar, por ejemplo, de patologías del acto.

\section{Del pasaje al acto más allá de la patologización}

Conviene explorar otras aristas del pasaje al acto. En primer término, Jean Allouch (2008) en su libro Marguerite o la Aimée de Lacan propon- 
drá que el pasaje al acto tiene la función de "hacer saber". Poner a los otros en posición de terceros, ya no como cómplices de la mostración sexual de la actriz, sino como partícipes de la indignación y el espanto que Aimée experimentaba. El pasaje al acto no es -como suele escucharse en las aulas o pasillos a modo de ecolalia lacaniana- sin Otro. En torno al caso Aimée, Allouch (2008) propone que lo que sucede es que el pasaje al acto -como el delirio mismo- tiene un valor demostrativo (pág. 253). Aquí encontramos una primera diferencia con la postura de Muñoz (2009) en torno al pasaje al acto:

En el pasaje al acto no se trata de mostración ni de demostración. Se trata de realización: es tratar lo real por lo real. En la realización, no se trata lo real mostrando el objeto en una escena -propio del tratamiento por mostración-, ni dando las coordenadas simbólicas que lo ciñen -propio de la demostración-, se lo trata por medio de su exclusión radical de la escena, pasándolo a lo real del mundo. (pág. 241).

Tal discusión entraña una complejidad que no se podrá abarcar aquí. Consideramos que la razón de la discrepancia es la siguiente: el estatuto del pasaje al acto una vez que Lacan construye el concepto de acto analítico en el seminario de 1967-1968. Allouch (2008) piensa que el concepto de pasaje al acto es absorbido por -o diluido en- el de acto analítico, mientras que Miller habla de una generalización de uno en el otro, ambos partiendo de la casi nula presencia que tiene el pasaje al acto en la enseñanza de Lacan a partir del Seminario 15. Muñoz (2009), en cambio, sostiene que, a pesar de esto, Lacan no deja caer el pasaje al acto. Es decir, el pasaje al acto conservaría un estatuto conceptual diferenciado, por lo que pensarlo como realización y no como demostración podría ser una forma, entre otras, de distinguirlo. Sin embargo, en este escrito es necesario tomar una postura siguiendo el hilo de la pregunta por el suicidio. Por tanto, concebir al pasaje al acto como una demostración nos sirve también para ubicarlo en relación al Otro; en este caso, en tanto barrado.

Esto nos permite politizar el pasaje al acto suicida: se trata de una apropiación del cuerpo cuya potestad se le suponía al Otro. Alguien sagaz replicaría: ¿qué sucede con el así llamado suicidio altruista? A lo que respondemos que la colectivización del cuerpo para un Occi- 
dente individualizante le deja ciertamente bastante perplejo, por no decir sin palabras. Además, poniendo por caso los motivos religiosos: un Dios que requiere sacrificios es un Dios que está en falta. Lo que se pone en juego en el suicidio es el pasaje de la muerte como significanteAmo al significante de la falta en el Otro. La manera en la que esto se logre es la directriz que tomaremos para una ética del acto suicida.

Ya no queda lugar a dudas del vínculo que guarda el pasaje al acto suicida con la locura: aquello que pone en falta al Otro en tanto sociedad normalizante. No sólo es asunto de su procedencia psiquiátrica sino de aquello de lo que la psiquiatría se hacía cargo.

Ahora, la relación entre acto analítico y pasaje al acto nos orientará para no caer en una dualidad en la que, por un lado, estaría el pasaje al acto suicida, cuyo paradigma sería la melancolía (y aunque no abiertamente admitido, abordado como algo patológico); y por otro, los suicidios como acto puro, simbólico, ético. Aunque es Lacan (2001/1974) mismo quien, en su conferencia "La tercera", da pie a esta lectura:

Yo, en cambio, les debo [se refiera a los estoicos] el respeto que le tengo al suicidio. Desde luego, no a suicidios basados en una bobería, sino esa forma de suicidio que es el acto propiamente dicho. No hay que malograrlo, por supuesto. Si se malogra no es un acto. (pág. 86).

Si alguien de inmediato sabe qué formas de suicidio son basados en una bobería, claramente no está pensando desde el psicoanálisis. Lo que no significa que no exista ningún suicidio basado en boberías, pues esto supondría caer en un juicio universal negativo. Pero ¿cómo saber qué razones son dignas para darse muerte? ¿Nos regimos, como psicoanalistas, por el principio de realidad? Alguien podría pensar en un adolescente que se mató por problemas que para sus padres eran meras bagatelas. Quizá era un acting out, quizá se le pasó la dosis, quizá tropezó antes que lanzarse, no estaba del todo decidido; pero una vez muerto, ¿hay bobería? Es menester cuidarse también del adultocentrismo. Pues desde el momento en que un acting out o un acto fallido llevan a consecuencias irreversibles, se convierten en pasajes al acto. 
Como se ve, Lacan permite varias posturas. La nuestra: no creemos que la condición para que un suicida participe del acto logrado sea estudiar estoicismo o tener algún parentesco con Séneca y Cicerón. Si el pasaje al acto se separa tajantemente del concepto de acto que Lacan comienza a formular a partir del acto analítico y se aplica la distinción al suicidio, quedaría que los suicidios por acting out o pasaje al acto serían malogrados. No estamos conformes con esto, pues podría seguir conservando el sentido psiquiátrico del pasaje al acto como patológico e impulsivo (en la jerga psicoanalítica como "asubjetivo" y pulsional). También porque podría estar ignorando que el acting out y el pasaje al acto forman una comunidad de estructura (Muñoz, 2009). Habría que pensar en los casos de cartas suicidas o suicidios rituales (véase el rito de suicidio japonés, seppuku) donde hay claramente montada una escena al Otro, siendo a su vez pasajes al acto. Admitimos la diferencia conceptual entre acting out, pasaje al acto y acto; empero, no nos parecen recipientes aislados sino vasos comunicantes. $\mathrm{Y}$ en cuanto al suicidio se refiere, tendría que proponerse la absorción del pasaje al acto en el concepto de acto.

En ello seguimos a Jean Allouch (2004), quien señalará que:

No hay "pasaje" al acto, el "pasaje al acto" es un concepto denominado falazmente, si con ello entendemos que algo lingüístico se realizaría en el acto. Por el contrario, el acto realiza algo a lo que el lenguaje de ninguna manera puede acceder. (págs. 42-43).

De este modo, el pasaje al acto no es el pasaje a la acción de lo que no pudo ser puesto en palabras. Habría, en cambio, que entenderse pasaje en un sentido más radical: un paso hacia el abismo, como Empédocles lanzándose al volcán Etna.

\section{Hacia una ética del acto suicida}

En la clase del 23 de enero del 63, durante el seminario La angustia, Lacan puntualiza: "Si ustedes quieren referirse a la fórmula del fantasma, el pasaje al acto está del lado del sujeto en tanto que este aparece borrado al máximo por la barra" (Lacan, 2007/1962-1963, pág. 128). 
Lo que el sujeto experimenta con la barra es del orden del embarazo, porque está también embarrado.

Resulta entonces paradójico que el pasaje al acto se localice justo donde la barra borra al sujeto barrado. Habría que recordar esta suerte de cacofonía para no concluir que la tachadura es posible solamente en el neurótico, el único que obtuvo la gracia divina de la castración (mediante el significante paterno, por supuesto) y que lo ubicó a salvo de la estructura psicótica y perversa. Si el pasaje al acto es transestructural, también lo es el suicidio. El suicidio no es sin sujeto. Esto permite cuestionar una consecuencia del afán clasificatorio a menudo latente en la distinción psicoanalítica entre tres estructuras: la primacía de la norma, que en este caso sería sostenida por la Ley y sustituida por la metáfora paterna; la instauración del significante Nombredel-Padre como posibilidad contra el destino funesto del abismo de la catatonia, el autismo, la paranoia, etc.; en fin, en último término: una apología a la edipización neurótica. Y así, como no hay deseo sin castración, quienes forcluyen el significante Nombre-del-Padre, o quienes desmienten la falta en el Otro, psicóticos y perversos, ¿no serían sujetos del deseo? O lo que es lo mismo: ¿la ética del psicoanálisis sólo abarca el campo de las neurosis? Más todavía: ¿de las neurosis en sesión con un analista? De responder afirmativamente, se estaría en la cúspide del elitismo edípico indistinguible del económico.

La experiencia analítica no se puede reducir a los consultorios privados, pues también discurre por otros territorios; dígase escuelas, hospitales, universidades, textos, ciberespacio... Acaso sea cuestión de ir pensando más topológicamente.

Lacan apunta a desprender al psicoanálisis de una conducción moral y contaminada de ideales, proponiendo para ello una ética. A diferencia de la ética aristotélica, no es la idea del bien la que se encuentra en el corazón de la discusión.

Pero decir el bien ya es una metáfora, un atributo. Todo lo que califica las representaciones en el orden del bien está preso en la refracción en el sistema de descomposición que le impone las estructuras de las facilitaciones inconscientes, la complejificación del sistema significante de los elementos. (Lacan, 2015/1959-1960, pág. 92). 
Además, tal funcionamiento significante va más allá del principio del placer; es decir, incluye esa experiencia imposible de insertar en un orden natural, llamada por Freud pulsión de muerte. De allí que el deseo de vivir y una ética sostenida en ello nos resulte cuestionable. Más bien ello responde a políticas sobre la vida y los cuerpos, como nos lo muestra la histórica condena al suicidio. Lo que llama la atención es que Lacan no plantea simple y sencillamente una ética del Eros sobre la pulsión de muerte, reforzar la pulsión vital y caso cerrado. Claramente se da cuenta que lo que se escapa del principio de placer es el meollo del asunto. No es casualidad, entonces, que haya invocado para pensar la ética del psicoanálisis a dos personajes transgresores y suicidas: Antígona y Edipo.

El fin de Antígona nos presenta la sustitución de no sé qué imagen sangrienta de sacrificio que realiza el suicidio místico. Ciertamente, a partir de cierto momento, ya no sabemos qué pasa en la tumba de Antígona. Todo nos indica que lo acaba de suceder se realiza en una crisis de manía, habiendo llegado Antígona a ese nivel en que perecen igualmente Áyax y Hércules -dejo de lado el fin de Edipo-. (Lacan, 2015/1959-1960, pág. 366).

Aquí Lacan se está refiriendo a la tragedia Áyax de Sófocles y probablemente al Heracles de Eurípides. Quedará pendiente abordar el suicidio místico y su relación, que consideramos estrecha, con la lógica del no-todo.

Esta es la preferencia con la que debe terminar una existencia humana, la de Edipo, tan perfectamente lograda que no muere de la muerte de todos, a saber, de una muerte accidental, sino de la verdadera muerte, en la que él mismo tacha su ser. (Lacan, 2015/19591960, pág. 376).

Nuevamente aparece aquí la tachadura, la barra. Hay que considerar que el exilio equivale en Edipo al fenecimiento, por lo que la muerte biológica no circunscribe el alcance de cómo el psicoanálisis puede abordar el suicidio. Y es que el estatuto ético del suicidio se juega allí en lo que Lacan (2015/1959-1960) llamó entre-dos-muertes: porque el significante mortifica el cuerpo y lo lleva más allá del plano biológico. 
Podemos comulgar, en el terreno práctico, con Thomas Szasz (2002) o Jean Améry (2005/1976) al proponer el suicidio como derecho inalieanable; no obstante, nuestro punto de partida no es la persona física sino el cuerpo atravesado por el significante (entre-dosmuertes), lo que significa incluir la locura en el espectro. Sostener que la razón y la voluntad determinen si un suicidio es ético es caer en una trampa. Es seguir interpelando al suicida a que rinda cuentas ante un tribunal. Que el cogito es un sujeto que decide sobre su cuerpo cual si fuese su propiedad. En cambio, en aquello que Lacan (en el Seminario 20) llama la sustancia gozante, no se trata de un cuerpo comandando por un alma: el cuerpo viene del Otro y el suicida lo desterritorializa. Pero no le pertenece a nadie. Tampoco es una propiedad privada y eso lo demuestran, p. ej., los kamikazes. El suicidio es un acto de apropiación. Y una ética de tal acto se debe fundar en los efectos de dicha apropiación y no en las supuestas causas, ni en qué tan convincentes estas sean.

Esto se articula con lo que propone Herman Burger (2017/1988) en su Tractatus logico-suicidalis: “(...) la lógica de la muerte no admite los motivos del 'para qué' ni del 'por qué'. Esa lógica, a su vez, sustituye el motivo por una tautología: 'Se suicidó porque se suicidó'” (pág. 57).

Es sólo Nachträglich, retroactivamente, que el sujeto aparece y algo puede ser leído.

La ética del psicoanálisis es una ética del deseo, pero si se reduce este a la estructura neurótica, se estaría llevando a cabo una colonización. La locura suicida (sin decir por ello que todo suicida sea psicótico) obliga a pensar la ética más allá de los divanes. "Antígona lleva hasta el límite la realización de lo que se puede llamar el deseo puro, el puro y simple deseo de muerte como tal. Ella encarna ese deseo" (Lacan, 2015/1959-1960, pág. 348). El bien y la belleza, menciona Lacan, son velos que cubren este horror del deseo radical, y el psicoanálisis supo ubicarlo con sagacidad. Pero Antígona no parece alguien que necesitase visitar a un analista, en ella ya estaba todo decidido. El pasaje de una ética del psicoanálisis a una del acto suicida es aquel de los límites de un análisis. 
En una conferencia en la Universidad de Yale, de manera lacónica, Lacan puntualiza: "Un análisis no tiene que ser llevado demasiado lejos. Cuando el analizante piensa que es feliz de vivir, es suficiente" (Lacan, 1975, pág. 12). Si el psicoanálisis muchas veces no ha estado a la altura de hablar del suicidio no tendría que sorprendernos, ni tampoco cabría exigírsele. Porque se piensa la ética del psicoanálisis meramente como una continuación del freudismo y su apología a las potencias de Eros. El deseo se convierte apresuradamente en una suerte de Eros lacaniano. De este modo, la idea de Lacan de que "de la única cosa de la que se puede ser culpable, al menos en la perspectiva analítica, es de haber cedido en su deseo" (Lacan, 2015/1959-1960, pág. 390), aparece como aplicable a distintos campos, entre ellos el de la melancolía. El mismo Lacan (1993/1974), en Psicoanálisis, radiofonía y televisión, la llama "cobardía moral". Y debido al vínculo que existe entre la melancolía y el suicidio (y a que a muchos les sea prácticamente imposible concebir que haya suicidios alegres), la patologización no se hará esperar.

Entonces ¿qué estatuto para el suicidio melancólico? ¿Es, en tanto plétora de goce y obstrucción del deseo, la antípoda de la ética psicoanalítica? Pensar que el suicidio melancólico no puede tener estatuto de acto, sino exclusivamente de pasaje al acto, pudiera estar respondiendo más bien a la angustia y el horror de los analistas frente a los alcances de la clínica.

Sucede que los conceptos pueden sufrir el infortunio de ser manipulados desde distintas disciplinas que imprimen su propia orientación teórica y clínica. En el caso de la psiquiatría -y también de la psicología- es palpable que aquello que pasa al acto pertenece al campo de la transgresión. Creonte, el tío de Antígona, ante quien su deseo se subleva, representa todo el mundo de los dispositivos psi.

Como bien dijo Thomas Szasz (2002): "Los enemigos principales que la psiquiatría del siglo XIX debía combatir eran el abuso de uno mismo y el autoasesinato (es decir, la masturbación y el suicidio). Ambas conductas se convirtieron también en objetivo principal de los psicoanalistas" (pág. 47). No tendría que sorprendernos si aún el uso de ciertos conceptos pudiese entrañar un pacto silencioso con la mo- 
ral, y más explícito con el plano jurídico. Podría hablarse incluso de un isomorfismo entre estos ámbitos con lo que Foucault (2007/19741975), en el curso en el Collège de France intitulado Los anormales, llama la higiene pública:

La psiquiatría, tal como se constituyó entre fines del siglo XVIII y principios del XIX (...) no se caracterizó como una especie de rama de la medicina general. La psiquiatría funciona -a principios del siglo xIx y ya avanzado éste, quizá hasta alrededor de 1850- no como una especialización del saber o la teoría médica, sino mucho más como una rama especializada de la higiene pública. (pág. 115).

Para legitimarse como un discurso de saber médico, dice Foucault (2007/1974-1975), la psiquiatría tuvo que realizar dos codificaciones simultáneas: la locura como enfermedad y como peligro. Ambos aspectos van a consolidar el cuerpo institucionalizado que es la psiquiatría hasta nuestros días. La psicología se ha nutrido tan ampliamente de la psiquiatría y las ciencias biomédicas a tal grado que a veces es difícil diferenciarlas. Pero más presente está el campo del peligro, ya no sólo de la locura, sino de todo aquello que cae bajo el conjunto de la prevención. El suicidio es algo que, desde el biopoder, se busca prevenir. Una ética del acto suicida es, ante todo, anti-psi.

A pesar de la posición crítica que Foucault mantuvo hacia el psicoanálisis, aquí somos más de la opinión de Jean Allouch (1998) cuando dice que "la posición del psicoanálisis, digo, será foucaultiano o no será más" (pág. 169). Un psicoanálisis foucaultiano es aquel que deja caer, en un legítimo pasaje al acto, la función psi.

En la vena de Foucault y Deleuze, Allouch (1998) propone desprender al psicoanálisis del vocablo psi, en aras justamente de ir más allá de la función psi como dispositivo.

Y en esa organización de los sustitutos disciplinarios de la familia, con referencia familiar, constatamos la aparición de lo que llamaré la función psi, es decir, la función psiquiátrica, psicopatológica, psicosociológica, psicocriminológica, psicoanalítica, etc. Cuando digo "función" no sólo aludo al discurso sino a la institución y al propio individuo psicológico. Creo que ésa es, en verdad, la función de 
esos psicólogos, psicoterapeutas, criminólogos, psicoanalistas, etc. ¿Y cuál es si no ser los agentes de la organización de un dispositivo disciplinario que va a ponerse en marcha, a precipitarse, cuando se produzca un vacío en la soberanía familiar? (Foucault, 2007/ 19731974, pág. 110).

Consideramos que es a partir de la enseñanza de Lacan donde el psicoanálisis puede trazar un sendero alterno a la función psi. Allouch (2015), en su conferencia "El psicoanálisis será foucaultiano o no será", menciona que "lo que Lacan y Foucault rechazan entonces no son solamente las vías psiquiátricas y psicológicas de la normalización, ni solamente la exigencia equívoca de un pensamiento sistematizado, rechazan también al sujeto fenomenológico donante de sentido" (s.p.). Con esto último se refiere al inconsciente psicologizado, aquel de los instintos (sic) reprimidos y demás.

Más adelante, hacia el final de la conferencia:

Basándose en que el psicoanálisis proviene de otra genealogía, diferente y más antigua, Foucault le ofrece la posibilidad de "calmar" su medicalización indebida, de ejercer como "técnico de subjetivación" que sabría atenerse a los términos mismos que le son dirigidos. El psicoanálisis será "foucaultiano" desde el momento en que haya sabido poner un término a esa mezcla teratológica de dos metodologías que persisten en ella (hacemos como si "clínica" tuviera el mismo sentido en la psiquiatría y en el psicoanálisis). (Allouch, 2015, s.p.).

La genealogía es de las prácticas que ponen en juego la relación del sujeto con la verdad. No es azaroso que Lacan haya erigido el análisis a la dignidad de un acto, y haya optado, para titular a su Seminario 15, por ese vocablo y no el de técnica, método, ni siquiera clínica.

(...) en la dimensión del acto inmediatamente surge ese algo que implica un término como el que acabo de mencionar, a saber, la inscripción en alguna parte, el correlato del significante, que en verdad, no falta jamás en lo que constituye un acto: puedo acá caminar a lo largo y a lo ancho mientras les hablo, esto no constituye un acto, pero si un día, por franquear un cierto umbral yo me pongo fuera de la ley, este día mi motricidad tendrá valor de acto. (Lacan, 1967-1968, pág. 4). 
El paso del analista, al proponerse como tal, es un acto, diferenciable fenoménicamente al del suicida, pero acaso sólo en eso. En el Seminario 22, RSI (clase del 18 de febrero de 1975) aparece que:

La muerte no es abordable más que por un acto; todavía, para que sea logrado, es preciso que alguien se suicide sabiendo que eso es un acto, lo que sólo sucede muy raramente. Aunque eso haya estado muy difundido en cierta época, en la época en que la filosofía tenía cierto alcance, un alcance distinto que el de sostener el edificio social. (Lacan, 1974-1975, s.p.).

No existe una estadística que pueda develar la frecuencia de un acto logrado. Suicidarse sabiendo que es un acto, ¿debe interpretarse como una mera deliberación? Esa sería una lectura bastante ingenua, poco advertida del descubrimiento freudiano. No creemos que Lacan vaya en esa dirección. Si sucede raramente, ¿habrá de inferirse que la mayoría son malogrados o fallidos? Otra trampa. Pero definitivamente, no todos los suicidios son actos logrados. Desde nuestra postura, un suicidio malogrado sería cuando el deseo traiciona la deliberación. Pero no basta con una decisión racional para que haya acto logrado. Es decir, también hay actos logrados de locura. Cabría preguntarle a Lacan si ese saber sobre el acto no sólo remita a los estoicos o a un samurái haciéndose el seppuku, sino a los efectos de un análisis. Esto puede aterrar a más de uno. Pero hacia esos lugares habría que dirigir la pregunta por una ética del acto suicida.

En el seminario El acto psicoanalítico (clase del 13 de marzo del 68), Lacan (1967-1968) pronuncia lo siguiente:

En efecto, si lo que hay del saber deja siempre un residuo, un residuo de algún modo constituyente de su estatuto, la primera cuestión que se plantea es a propósito del partenaire, del que allí es, no digo ayuda sino instrumento para que se opere algo que es la tarea psicoanalizante al término de la cual el sujeto, digamos, está advertido de esta división constitutiva, después de lo cual, para él, algo se abre que no puede llamarse de otro modo distinto que pasaje al acto, pasaje al acto, digamos, esclarecido, es justamente por saber que en todo acto hay algo que, como sujeto, se le escapa, que vendrá a hacer incidencia y que al término de este acto, la realización 
es, por el momento, por lo menos, velada por lo que hay del acto a cumplir como su propia realización. (pág. 171).

¡Vaya manera de despsiquiatrizar el pasaje al acto! Hablar del fin de análisis como pasaje al acto, cuya realización está velada en el acto a cumplir. ¿Esto podría ser leído como una disyunción entre fin de análisis/devenir analista y suicidio? Pero ¿no podría esto llevarnos a una dicotomía en la que estarían, por un lado, los iluminados, advertidos de la falta en el Otro, que pagaron y se sometieron al trabajo analítico, y por otro, los suicidas, melancólicos, traidores a su deseo? ¿Qué es entonces el opuesto a ese pasaje al acto esclarecido? Allouch (2008) propone que:

\begin{abstract}
Al hablar de pasaje al acto advertido, ¿dejamos tal vez entrever que existiría algún otro tipo de pasaje al acto que no lo sería? Esto legitimaría la existencia de dos conceptos distintos: el de acto (equivalente al de pasaje al acto advertido) y el de pasaje al acto (en el que sobreentendemos que no es advertido, que es ciego, ignorante). No se trata de eso exactamente: tenemos que cuidarnos, aquí también, de no caer en la trampa binaria: el todo o el nada en la relación del sujeto al saber. (pág. 398).
\end{abstract}

Para el suicida tampoco hay trampas binarias. El todo es el nada. El vel es letal: como en el caso de decir "libertad o muerte". No debe entenderse esto como un nihilismo. El tema no se agota en una falta de sentido vital: véase Deleuze, nietzscheano, vitalista, aunque gravemente enfermo. En su caída se agenció un nuevo cuerpo. Por otro lado, dice Thomas Szasz: “El mártir cristiano quería acabar con su vida precisamente porque la valoraba, pero no en el estado existencial en que se hallaba" (2002, págs. 125-126). Piénsese también en quien se da muerte por más vida: un monje budista arde a lo Bonzo en acto revolucionario.

¿Cuál sería la característica que abriría dos modalidades de pasaje al acto?

Esos dos modos del pasaje al acto, no obstante, difieren en cuanto a la relación del sujeto con el Otro. En el pasaje al acto advertido, el Otro está barrado, reducido al residuo esencial del saber y rechaza- 
do como tal, en el pasaje al acto como advertencia el Otro permanece sin barrar, el sujeto trata de cierta manera, en su propio pasaje al acto, una inaceptable falta de saber en el lugar del Otro. (Allouch, 2008, pág. 398).

La distinción no es, entonces, entre esclarecido e ignorante, sino entre Otro barrado y sin barrar. Aventuremos una hipótesis: en cuanto al suicidio se refiere, los suicidios como advertencia, podrían ser aquellos de corte paranoico (como el pasaje al acto de Aimée) que buscan la destrucción del Otro; Hitler en el búnker: ellos o nosotros, todo o nada. Como se ve, comienza por otra lógica, pero culmina en la tautología. Al final, el Otro aparece barrado. El nazismo es el significante de la falta en el Otro en tanto fracaso del proyecto ilustrado y de la Historia concebida como progreso.

Suicidio advertido: el caso de Philipp Mainländer, quien, al haber publicado su obra Filosofía de la redención, se dio muerte por ahorcamiento. Su escrito es un elogio al suicidio y al anti-natalismo cuya escasa fama se debe, seguramente, a sus subversivas coordenadas éticas -y decimos éticas porque para el filósofo están en función de la libertad-. No obstante, su filosofía "no exhorta al suicidio; pero en aras de la verdad, debió destruir los poderosos y temibles motivos que se le oponen" (Mainländer, 2019/1876, pág. 360).

Pero esta división no resuelve el problema de los suicidios éticos, sino que apenas lo plantea. Después de todo, acaso matarse fuese lo más ético que Hitler pudo hacer, mientras que Mainländer proponía un mundo donde el suicidio está en función del deseo de un Dios suicida. Es un asunto de topología, no de polaridades. Tenemos casos límites, como el de Jorge Cuesta, de quien no se sabe si se suicidó; pero de haber sido así, pudo ser en medio de un brote psicótico. Accidente o no, enloquecido o no, su cuerpo se rebeló contra el confinamiento y las potencias de muerte psiquiátricas.

Freud concebía a la vida como la lucha entre dos grupos pulsionales cualitativamente diferenciados: Eros y pulsiones de muerte. Por lo que el suicidio sería una salida del conflicto psíquico dialéctico. Soportar la tensión no deja de ser opuesto al suicidio, incluso desde cier- 
ta óptica filosófica. Albert Camus (1995/1942), por ejemplo, propone la figura del hombre absurdo, aquel que sostiene la incompatibilidad entre el individuo y el mundo, entre la aspiración de encontrarle un sentido a la vida y la inexorable carencia de uno. Por lo que el hombre que admite con una sonrisa en el rostro el suplicio de Sísifo no es aquel que se suicida. El suicida, en cambio, sería aquel que no tolera lo absurdo. En una dirección diferente se encontraría Antígona, quien no pretende ser un Sísifo feliz, sino enterrar a su hermano, dando la vida por ello. También habría que agregar que una ética del acto suicida no tiene por qué reducirse a la dimensión trágica.

La ética del psicoanálisis que Lacan elabora no se reduce a la directriz de soportar la tensión de la vida. El acto suicida coloca al psicoanálisis frente a sus límites y visibiliza los vínculos que aún mantiene con la psiquiatría y la psicología. Divergente con los designios de la psicopatologización, muchas veces escamoteados desde el mismo psicoanálisis, la revisión aquí expuesta está comprometida con que al suicidio, como acto, una ética le atañe. Una ética que apunte a los efectos más que a las causas, que permita ir más allá de la pura voluntad de destrucción y que confronte la condena y necedad gazmoñeras.

\section{Referencias}

Allouch, J. (1998). El psicoanálisis, una erotología de pasaje. Litoral, Ediciones de la École Lacanienne de Psychanalyse.

Allouch, J. (2004). La sombra de tu perro. Discurso psicoanalítico - Discurso lesbiano. El cuenco de plata, Ediciones literales.

Allouch, J. (2008). Marguerite o la Aimée de Lacan. El cuenco de plata, Ediciones literales.

Allouch, J. (2015). El psicoanálisis será foucaultiano o no será. En Laufer, L. y Squverer, A. (dirs.), Foucault et la psychanalyse [Verónica Martínez (Trad.)]. Herman Éditeurs. http://www.revistanacate.com/wp-content/uploads/2015/11/El-psicoana \%CC \%81lisis-sera \%CC $\% 81$-foucaultiano-o-no-sera\%CC\%81-Jean-Allouch.pdf

Améry, J. (2005/1976). Levantar la mano sobre uno mismo. Pre-textos.

Burger, H. (2017/1988). Tractatus logico-suicidalis. Matarse uno mismo. Pre-textos. 
Camus, A. (1995/1942). El mito de Sísifo. Alianza Editorial.

Evans, D. (2007). Diccionario introductorio de psicoanálisis lacaniano. Paidós.

Foucault, M. (2007/1973-1974). El poder psiquiátrico. Curso en el Collège de France. Fondo de Cultura Económica.

Foucault, M. (2007/1974-1975). Los anormales. Curso en el Collège de France. Fondo de Cultura Económica.

Freud, S. (1992/1905). Fragmento de análisis de un caso de histeria. En J. Strachey (Ed.), J. L. Etcheverry \& L. Wolfson (Trads.), Obras completas (Vol. VII, págs. 1-98). Amorrortu.

Kris, E. (1951). Psicología del yo e interpretación en la terapia psicoanalítica [trad. Michel Sauval a partir de la versión de Adam, J. aparecida en ORNICAR no. 46, julio/sep., 1988].

Lacan, J. (1967-1968). Seminario 15. El acto psicoanalítico [trad. y notas de Ricardo Rodríguez Ponte]. Kriptos.

Lacan, J. (1974-1975). Seminario 22. RSI [trad. y notas de Ricardo Rodríguez Ponte].

Lacan, J. (1975-1976). Conferencias y charlas en universidades norteamericanas [trad. y notas de Ricardo Rodríguez Ponte]. En Scilicet, (6/7). Éditions du Seuil.

Lacan, J. (1993/1974). Psicoanálisis, radiofonía y televisión. Anagrama.

Lacan, J. (2001/1974). La tercera. En Intervenciones y textos 2. Manantial.

Lacan, J. (2005/1932). De las psicosis paranoicas en sus relaciones con la personalidad. Siglo XXI Editores.

Lacan, J. (2005/1961). La dirección de la cura y los principios de su poder. En Escritos 2. Siglo XXI Editores.

Lacan, J. (2007/1950). Acerca de la causalidad psíquica. En Escritos 1. Siglo XXI Editores.

Lacan, J. (2007/1962-1963). El seminario de Jacques Lacan, libro 10. La angustia. Paidós.

Lacan, J. (2015/1959-1960). La ética del psicoanálisis. En El seminario de Jacques Lacan, libro 7. La ética del psicoanálisis. Paidós.

Laplanche, J., Pontalis, J. y Lagache, D. (2004/1967). Diccionario de psicoanálisis. Paidós.

Mainländer, P. (2019/1876). Filosofía de la redención. Xorki.

Muñoz, P. (2009). La invención lacaniana del pasaje al acto. De la psiquiatría al psicoanálisis. Manantial.

Szasz, T. (2002). Libertad fatal. Ética y política del suicidio. Paidós. 